\title{
Use of Repeated Measures Analysis for Evaluation of Genetic Background of Dairy Cattle Behavior in Automatic Milking Systems
}

\author{
S. König, ${ }^{11}$ F. Köhn, ${ }^{*}$ K. Kuwan,† H. Simianer, ${ }^{\star}$ and M. Gauly* \\ *Institute of Animal Breeding and Genetics, University of Göttingen, 37075 Göttingen, Germany \\ †Vereinigte Informationssysteme Tierhaltung (VIT), Heideweg 1, 27283 Verden, Germany
}

\begin{abstract}
Milking frequencies measured at official test days were used with repeated measurement analysis to reveal the environmental and genetic impact on the milking frequency of cows in automatic milking systems. Repeated measurements were 3 test-day observations per cow within days in milk (DIM) classes, with 1,216 cows in DIM class 1 (d 0 to 99), from 1,112 cows in DIM class 2 (d 100 to 199), and from 1,004 cows in DIM class 3 (d 200 to 299) kept in 15 farms. Selection criteria for models analyzing repeated measurements were Akaike and Schwarz Bayesian values, which favored the autoregressive $[A R(1)]$ covariance structure over the compound symmetry model. Results from the AR(1) model indicated a significant impact of fixed herd and parity effects. Milking frequencies decreased with increasing parities and were greatest for first-parity cows. High daily milk yield was associated with higher milking frequencies. Heritabilities for milking frequency were $0.16,0.19$, and 0.22 in DIM classes 1,2 , and 3, respectively, from the AR(1) model. Higher heritabilities in the later stage of lactation were due to a substantial reduction of the residual variance. Genetic correlations between test-day milk yield and daily milking frequency were in the range of 0.46 to 0.57 for all DIM classes and between milking frequency and somatic cell score were near zero. For verification of results, milking frequencies of the same cows obtained from herd management programs were averaged within DIM classes. Heritabilities were slightly above the values from the AR(1) model. In conclusion, heritabilities for milking frequency in automatic milking systems are moderate enough to incorporate this behavioral trait in a combined breeding goal. The inevitable improvement of labor efficiency in dairy cattle farming demands such cows going easily and voluntarily in automatic milking systems.
\end{abstract}

Key words: automatic milking system, milking frequency, heritability, genetic correlation

Received December 5, 2005.

Accepted March 30, 2006.

${ }^{1}$ Corresponding author: skoenig2@gwdg.de
INTRODUCTION

Rydhmer (2005) described behavioral genetics as a fascinating and important area of research. The genetic background, the environment, and the interaction of heredity and environment result in the phenotypic expression of a behavior. Prior experiences analyzing behavior revealed complicating factors in distinguishing between genetic and environmental components, and these factors have to be considered to minimize the potential for confounding (Buchenauer, 1999). Another concern is that, especially in intensive systems, domestic animals may not express the full range of innate behavior when they are provided with food, shelter, and protection from predators (Schutz and Pajor, 2001). Compared with other branches of animal science, relatively little information on behavioral genetics in livestock is available. The ostensible reason is that traits of behavior are difficult to measure, and data are often subjective impressions of observers, which increases the residual component. Furthermore, experimental designs for behavioral studies demand a huge amount of work, which probably explains the lack of published studies (Rydhmer, 2005). Beside this, Faure (1994) indicated that measures of behavioral traits were frequently not normally distributed, which complicates the estimation of variance components. Another problem is that cattle are often kept in herds, so that many behavior patterns may be acquired by learning from group members, and it is difficult or even impossible to distinguish between innate and learned behavioral traits. In a review of the inheritance of behavior in farm animals, Hohenboken (1986) reported genetic effects on behavior, as determined by estimates of heritabilities. In addition, genetic differences have been found among breeds, breed crosses, strains, and selection lines. However, most of the published research involving cattle has been conducted on beef cattle (Le Neindre et al., 1995; Gauly et al., 2004).

Several studies (e.g., Gustafsson, 2004) have revealed the importance of temperament in dairy cattle. Trilk et al. (2005) evaluated labor time in farms using robotic milkers, also known as automatic milking systems (AMS). Compared with milking 3 times a day in a her- 
Table 1. Estimates of heritability for behavioral traits and genetic correlations between behavior and production traits in Holstein dairy cattle [adapted from Schutz and Pajor (2001) and supplemented by recent other publications]

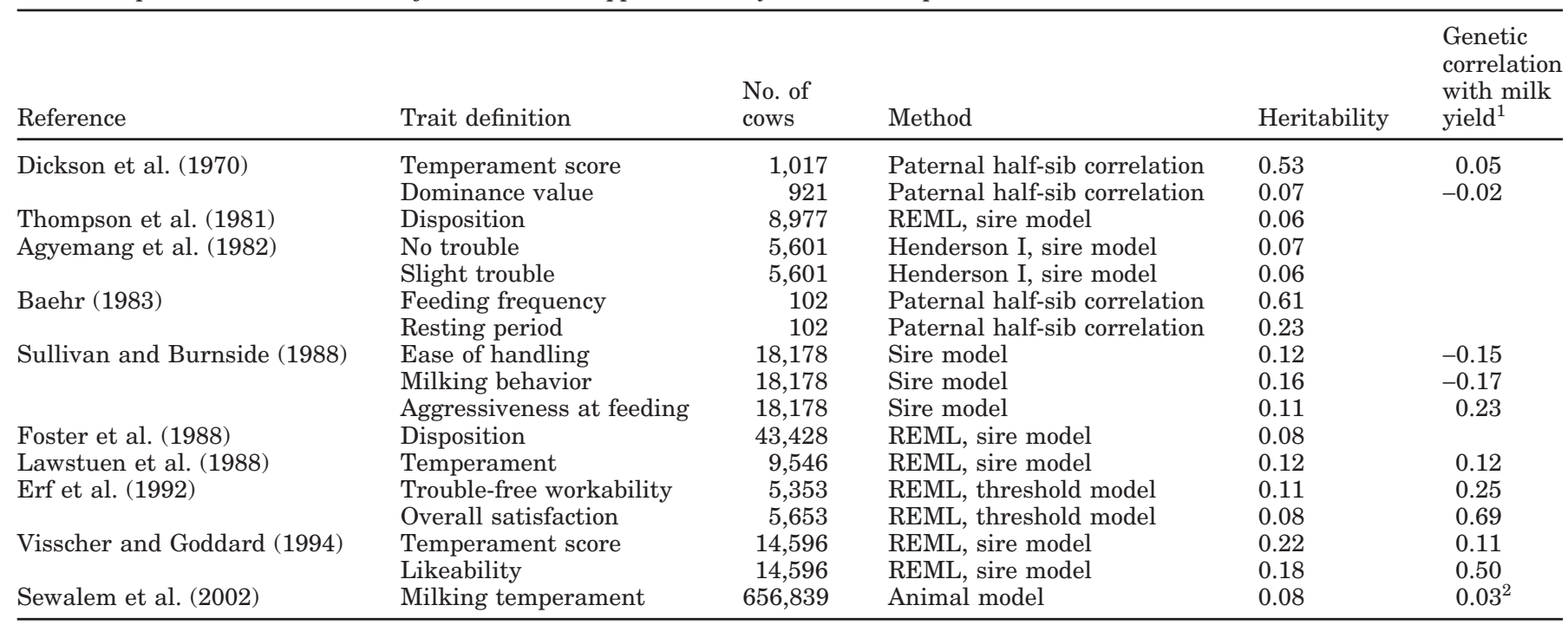

${ }^{1}$ Positive correlations are favorable; i.e., cows giving more milk have the desired temperament.

${ }^{2}$ Correlation between EBV of bulls.

ringbone parlor, the yearly requirement for milking with AMS, including additional time for milking unsuitable cows, was $6.3 \mathrm{~h}$ per cow lower. Nevertheless, the authors identified opportunities for potential improvements in labor with AMS; $29.9 \%$ of the labor was associated with moving cows to the automatic milking box. Presupposing a genetic component for behavior (the willingness of cows to enter the AMS) could be an important behavioral trait for selection decisions.

In early studies investigating the genetics of behavior in dairy cattle, Burnside et al. (1971) observed pronounced differences among breeds for percentages of animals culled for "bad" temperament. These results favored Ayrshires, followed by Jerseys, Holsteins, and Guernseys. A recent overview of estimated genetic parameters for temperament in dairy cattle was presented by Schutz and Pajor (2001). They reported recent estimates of heritability for temperament ranging from 0.08 to 0.25 (Table 1 ) and concluded that temperament may have the potential to be included in the breeding goal; however, the definition of temperament differed across studies.

A key aspect of AMS is that the cows decide when they will come to the milking area. Other than the study conducted by Baehr (1983), the results in Table 1 were based on subjective impressions of investigators. Baehr (1983) favored objective measurements, such as the repeated records of voluntary entrances of cows in a feeding station or the resting period of cows in their stalls.

Because of computing limitations, repeated records on an individual have often been averaged to decrease numbers of data. Estimated heritabilities using averages of multiple observations per cow and day have ranged from 0.23 to 0.61 . However, recent developments in mixed model theory and advances in computer software now allow for the implementation of random effects in the statistical model and the modeling of the covariance structure of the data. Modeling the covariance structure is especially important for the analysis of repeated measurements because measurements taken close in time are often more highly correlated than those taken further apart in time (Littell et al., 1997).

The objective of our study was to estimate genetic parameters for the automatically recorded behavioral trait "milking frequency" of cows in an AMS, including its correlation with production traits, by using different methods for analyzing repeated measurements. For selection to be effective, reliable estimates of genetic parameters of behavioral traits are needed to determine the amount of genetic variation. Correlations with other traits of economic importance are also required to define a combined breeding value in dairy cattle.

\section{MATERIALS AND METHODS}

\section{Data}

Fifteen farms in the northwestern part of Germany with the same type of AMS were used in the study. The main characteristic defining the sample of farms was that the entrance of cows in the milking box was mainly voluntary and regulations by employees were restricted 


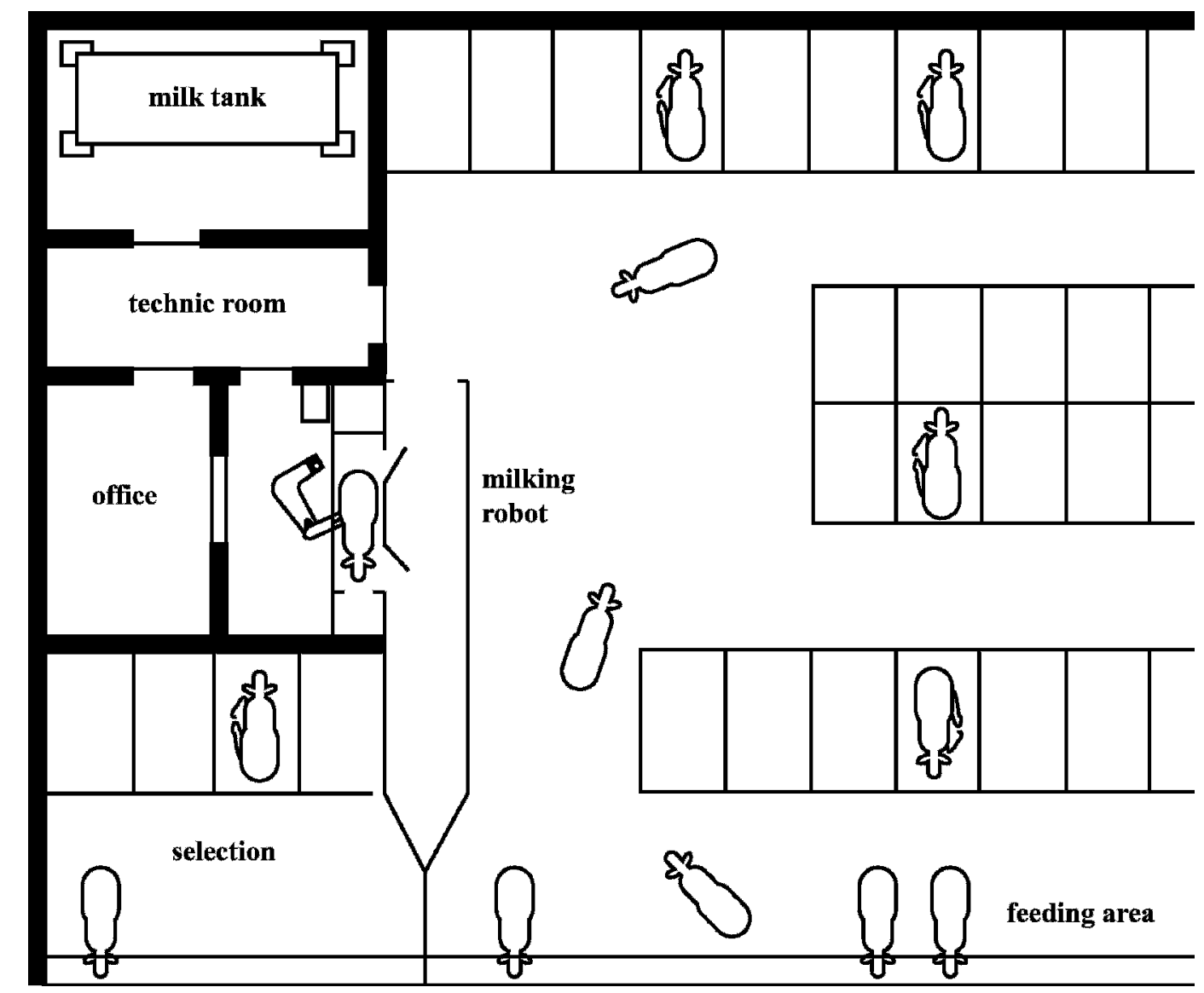

Figure 1. Schematic floor plan for voluntary traffic of cows in the automatic milking systems (AMS) used for our research design.

to a minimum. The feeding and management strategies across the farms were kept as constant as possible.

The general floor plan for voluntary traffic of cows is depicted in Figure 1. Concentrate feeds offered in the milking box and the innate desire to be milked were the only known motivators for cows to move into the AMS. Milking frequency entries and production records were available from 2 different data sets. Data set 1 comprised the results from the official milk recording scheme, which were taken in intervals of $4 \mathrm{wk}$ and utilized for the official national breeding value estimation. For official milk recording, a shuttle was connected to the AMS, a milk sample was taken, and milking frequency was counted for each milking over a 24-h period. The sample provided data about SCC. The procedure to transform AMS records for electronically measured milk yield and milk contents to 24-h equivalents was applied as described by Buenger et al. (2001). Data set 1 included cows calving in 2003 or 2004, and therefore, no repeated measurements of cows across parities were available. Bohlsen (2000) indicated different behavior of cows in AMS as a function of stage of lactation.
Based on these results, a general stratification of the data according to DIM after calving was done. The first DIM class was from d 0 to 99, DIM class 2 from d 100 to 199 , and DIM class 3 from d 200 to 299 after calving. Data for repeated measure analysis (data set 1 ) were 3 test-day observations per cow per DIM class. Numbers of cows were 1,216, 1,112, and 1,004 for classes 1,2 , and 3 , respectively.

In addition, milk yields from each visit in the milking box of the cows from data set 1 were recorded by the farmers using herd management programs. Daily milk yields and daily milking frequencies from all available entrances in the milking box were stored in data set 2 . Cows that were present for fewer than $80 \mathrm{~d}$ within DIM classes were excluded from both datasets. A complete overview of the data and the genetic structure is given in Table 2.

\section{Statistical Models}

Repeated Measure Analysis. Milking frequencies in the AMS were available from 3 different test days 
Table 2. No. of cows, no. of milking days, no. of daughters per sire, and average milking frequency (MF), milk yield (MY) and SCS for model 1 (repeated measure analysis), and model 2 (average observations) stratified by DIM classes

\begin{tabular}{|c|c|c|c|c|c|c|}
\hline Item & \multicolumn{2}{|c|}{ DIM class 1} & \multicolumn{2}{|c|}{ DIM class 2} & \multicolumn{2}{|c|}{ DIM class 3} \\
\hline No. of cows & 1,216 & 1,216 & 1,112 & 1,112 & 1,004 & 1,004 \\
\hline Average no. of daughters per sire ${ }^{2}$ & $\begin{array}{l}9.7 \\
(1 \text { to } 56)\end{array}$ & $\begin{array}{l}9.7 \\
(1 \text { to } 56)\end{array}$ & $\begin{array}{l}9.1 \\
(1 \text { to } 51)\end{array}$ & $\begin{array}{l}9.1 \\
(1 \text { to } 51)\end{array}$ & $\begin{array}{l}8.4 \\
(1 \text { to } 47)\end{array}$ & $\begin{array}{l}8.4 \\
(1 \text { to } 47)\end{array}$ \\
\hline $\begin{array}{l}\text { Average } \mathrm{MF}, \text { times/d } \\
\text { Average } \mathrm{MY}, \mathrm{kg} / \mathrm{d}\end{array}$ & $\begin{array}{r}3.00 \\
32.41\end{array}$ & $\begin{array}{r}3.05 \\
32.60\end{array}$ & $\begin{array}{r}2.97 \\
28.16\end{array}$ & $\begin{array}{r}2.98 \\
28.02\end{array}$ & $\begin{array}{r}2.70 \\
22.45\end{array}$ & $\begin{array}{r}2.81 \\
22.65\end{array}$ \\
\hline Average daily SCS & 3.44 & 3.53 & 3.51 & 3.54 & 3.69 & 3.69 \\
\hline
\end{tabular}

${ }^{1}$ For model 1: 3 repeated measurements (official test days per cow); for model 2: total no. of test days within DIM class for calculating average milking frequencies per cow and day.

${ }^{2}$ In parentheses: no. of daughters per sire from minimum to maximum.

for each cow within distinct DIM classes (data set 1). The statistical model included the fixed effects of the herd and the parity as well as a regression on milk yield and DIM up to the third polynomial degree to fit regression curves. Interaction between parity and milk yield in linear and exponential terms was also considered in the model. The nonsignificant regression coefficients of different polynomial structures were removed from the model by using type I sums of squares at $P<$ 0.05 , rather than likelihood ratio tests. Such a sequential analysis approach is appropriate for polynomial models (Littell et al., 1999). The final model thus included only significant fixed effects and covariates and random additive genetic and permanent environmental effects of cows and was formulated as

$$
\begin{gathered}
\mathrm{y}_{\mathrm{ijkl}}=\mu+\mathrm{H}_{\mathrm{i}}+\operatorname{parity}_{\mathrm{j}}+\mathrm{a}_{\mathrm{k}}+\mathrm{pe}_{\mathrm{k}} \\
+\beta_{1} \mathrm{MY}_{\mathrm{ijk}}+\alpha_{1} \mathrm{DIM}_{\mathrm{ijk}}+\mathrm{e}_{\mathrm{ijk} \mathrm{l}},
\end{gathered}
$$

where $\mathrm{y}_{\mathrm{ijkl}}=$ milking frequency of cow $\mathrm{k} ; \mu=$ overall mean effect; $\mathrm{H}_{\mathrm{i}}=$ fixed effect of herd $\mathrm{i} ;$ parity $_{\mathrm{j}}=$ fixed effect of parity $j ; a_{k}=$ random additive genetic effect of cow $\mathrm{k} ; \mathrm{pe}_{\mathrm{k}}=$ random permanent environment effect of cow k; $\mathrm{MY}_{\mathrm{ijk}}=$ milk yield of cow $\mathrm{k}$ in herd $\mathrm{i}$ and parity $\mathrm{j} ; \beta_{1}=$ linear regression of milking frequency on milk yield; $\mathrm{DIM}_{\mathrm{ijk}}=\mathrm{DIM}$ of cow $\mathrm{k}$ in herd $\mathrm{i}$ and parity $\mathrm{j} ; \alpha_{1}=$ linear regression of milking frequency on DIM; and $\mathrm{e}_{\mathrm{ijkl}}=$ random residual effect belonging to observation $\mathrm{y}_{\mathrm{ijkl}}$.

The ASREML program (Gilmour et al., 1998) was applied, which enables the user to directly address the covariance structure when analyzing repeated measures. Two covariance structures were investigated: compound symmetry (CS) and the first-order autoregressive [AR(1)] structure. First, the CS structure was fitted. This modeling implies that all records have the same variances over time and that all pairs of correla- tions within the same animal, parity, and DIM class are equal. It is thus assumed that the correlation is constant regardless of how far apart the measures are in time. The AR(1) covariance structure allows for nonconstant covariances (Wade and Quaas, 1993) and has only one parameter more than the CS structure. As suggested by Quaas (1984), the AR(1) structure was used for modeling the residual covariance structure. This combination structure specifies an interanimal random effect accounting for mean differences between animals and a correlation structure within animals that decreases with increasing time measures. The time between measures was defined as the time-dependent covariate DIM in model 1 . The equation for the linear mixed model in matrix notation and the modeling of matrices for the CS and AR(1) models are presented in detail by Sawalha et al. (2005a).

Selection of the most appropriate covariance structure was based on Akaike's information criterion (AIC; Akaike, 1973). Akaike (1973) proposed a simple and useful criterion for selecting the best-fit model among alternative models:

$$
\begin{gathered}
\text { AIC }=-2(\log \text { likelihood }) \\
+2(\text { number of variance parameters }) .
\end{gathered}
$$

Differences between AIC values are important, not the absolute size of AIC values. The model with the lowest AIC is considered the best. Another widely used information criterion is the Bayesian Schwarz information criterion (BIC), which takes into account model uncertainty as well. The BIC is stricter than AIC and is defined as

$$
\begin{aligned}
& \mathrm{BIC}=-2(\log \text { likelihood })-\log (\mathrm{n}) \\
& \times \text { number of variance parameters, }
\end{aligned}
$$


where $\mathrm{n}$ is equal to the number of records used in the analysis, as shown by Huisman et al. (2001). The third approach used to compare the goodness of fit between the 2 models was the likelihood ratio test.

Average Observations. Milking frequencies and milk yields per cow and day obtained from the herd management program (data set 2) were averaged within cows and DIM classes. Using average observations of repeated measurements is a commonly used procedure. For example this method was used by Gregory et al. (1997) for achieving normality of data for the ovulation rate of 6 consecutive estrous cycles in a beef cattle population. The ASREML software (Gilmour et al., 1998) was used to check significance of the fixed herd and parity effects as well as the effect of the covariate average daily milk yield, up to the third polynomial degree. Nonsignificant effects at the $P<0.05$ level were removed from model 2 , which was finally formulated as follows:

$$
\mathrm{y}_{\mathrm{ijkl}}=\mu+\mathrm{H}_{\mathrm{i}}+\text { parity }_{\mathrm{j}}+\mathrm{a}_{\mathrm{k}}+\beta_{1} \mathrm{MY}_{\mathrm{ijk}}+\mathrm{e}_{\mathrm{ijk} \mathrm{k}},
$$

where $\mathrm{y}_{\mathrm{ijkl}}=$ average milking frequency per day of cow $\mathrm{k}$ in the AMS within DIM class; $\mu=$ overall mean effect; $\mathrm{H}_{\mathrm{i}}=$ fixed effect of herd $\mathrm{i} ;$ parity $\mathrm{j}_{\mathrm{j}}$ fixed effect of parity $\mathrm{j} ; \mathrm{c}_{\mathrm{k}}=$ random additive genetic effect of cow $\mathrm{k} ; \mathrm{MY}_{\mathrm{ijk}}=$ average milk yield per day of cow $\mathrm{k}$ in herd $\mathrm{i}$ and parity $\mathrm{j}$ within DIM class; $\beta_{1}=$ linear regression of milking frequency per day on average milk yield per day; and $\mathrm{e}_{\mathrm{ijk} \mathrm{k}}=$ random residual effect belonging to observation $\mathrm{y}_{\mathrm{ijk} \mathrm{k}}$.

The AR(1) structure for modeling repeated measurements (model 1) and model 2 for average observations from the herd management program were used to estimate genetic correlations among traits. Genetic correlations among the daily milking frequency, daily milk yield, and SCS were estimated in a multivariate analysis by removing the covariate milk yield from model 1 and model 2. The daily SCC was log-transformed into daily SCS to achieve normality and homogeneity of variances as given by Ali and Shook (1980). For all analyses, relationships of cows were considered in an animal model traced back to base animals born after 1940 .

\section{RESULTS AND DISCUSSION}

\section{Covariance Structures}

Table 3 has the AIC, BIC, and likelihood ratio tests for the various models. The smallest values were obtained when applying the AR(1) structure. In addition, all of the calculated likelihood ratio statistics comparing the $\mathrm{AR}(1)$ and $\mathrm{CS}$ models were greater than the critical $\chi^{2}$ values. The smallest calculated statistic was

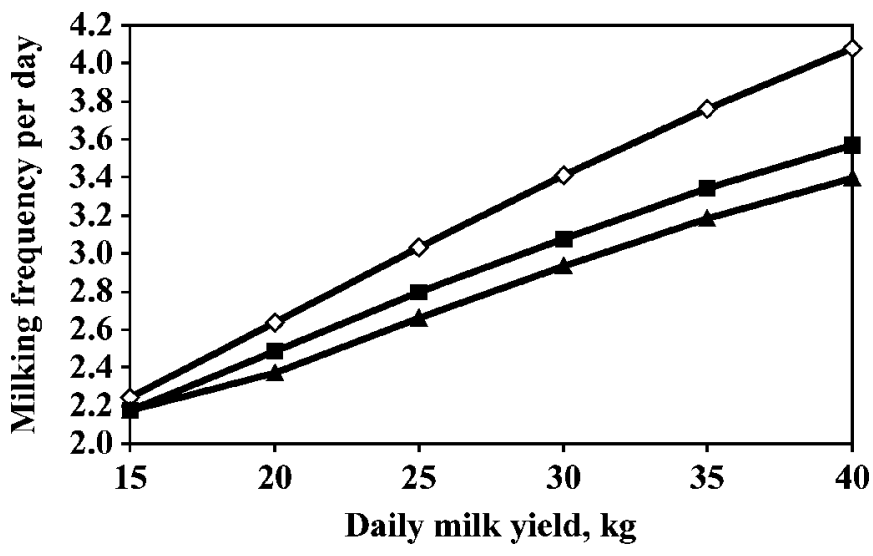

Figure 2. Least squares means for milking frequency per day in parity $1(\diamond), 2(\boldsymbol{\square})$, and $>2(\boldsymbol{\Delta})$ dependent on daily milk yield for DIM class 1 from 1 to $100 \mathrm{~d}$ after calving.

25 between the AR(1) model and the CS model for DIM class 2 . This value easily exceeded the critical $\chi^{2}$ value of 10.83 at $P=0.001$ with 1 degree of freedom. Littell et al. (1997) also reported advantages of using the AR(1) instead of CS. Based on the results for fertility in laying hens, Sharifi (2004) suggested to account for the time interval between repeated measurements in statistical models. Similar to our study, AIC values and BIC values for their data were smaller for the AR(1) structure than for the CS structure. Sawalha et al. (2005a) modeled AR(1) and CS structures for test day permanent environmental effects on milk production, and the AIC criterion was smaller for the AR(1) structure. Sawalha et al. (2005a) concluded that the AR(1) model was superior for variance component estimation for their data, although they found smaller estimates for heritabilities than with the CS model. A second analysis conducted by Sawalha et al. (2005b) clearly pointed out that the use of an AR(1) structure for short-term environmental effects is more appropriate for breeding value estimation than the simple CS structure. Their criterion for the goodness of fit in that study was the highest accuracy for estimated breeding values.

Estimates of autoregressive correlation coefficients $(\rho)$ for the residuals with the AR(1) model were in the range of 0.52 to 0.61 . Sawalha et al. (2005a) reported lower estimates in the range of 0.23 to 0.38 for test-day milk yields. They concluded that the small estimates of the correlation coefficient for residual effects is due to the fact that the AR(1) model also included permanent environmental effects that were assumed to be common for all test day records for each cow.

\section{Fixed Effects and Covariates}

The ANOVA for repeated measurements $[\mathrm{AR}(1)$ covariance structure] revealed significant effects of the 
Table 3. Akaike information criteria (AIC), Schwarz Bayesian information criteria (BIC), 2 log -L values for the CS and AR(1) covariance structure analyzing repeated measures and the AR(1) correlation coefficient $\rho$, stratified by DIM classes (smaller values within DIM classes indicate the superior model) ${ }^{1}$

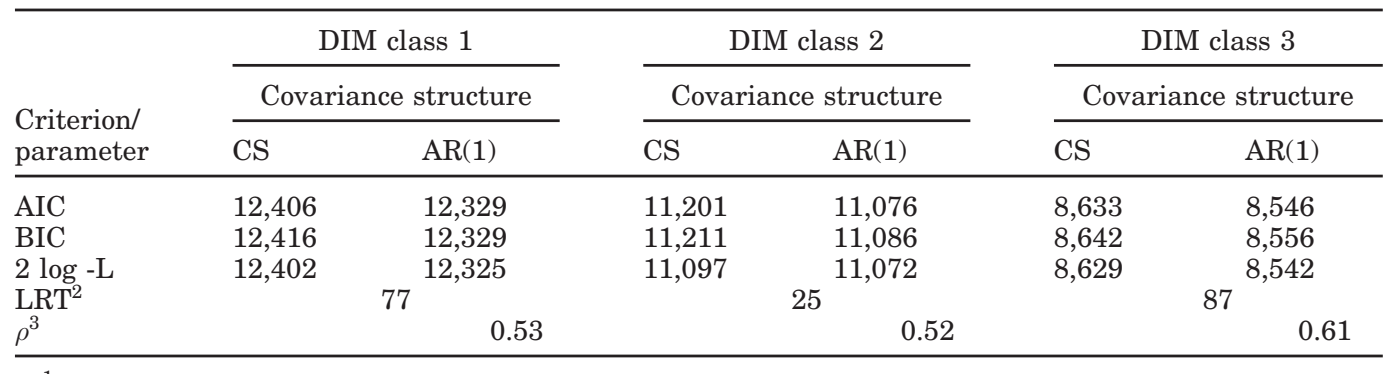

${ }^{1} \mathrm{CS}$ model is a simple repeatability model with compound symmetry covariance structure for milking frequency per day environmental effects; AR(1) model assumes autoregressive covariance structure for milking frequency per day environmental effects.

${ }^{2} \mathrm{LRT}=$ likelihood ratio test statistic for comparing CS models with AR(1) models.

${ }^{3} \mathrm{AR}(1)$ correlation coefficient.

herd $(P<0.001)$ and parity $(P<0.01)$ on milking frequency within all DIM classes. Similar results were obtained using model 2 and analyzing average observations within DIM classes. The least squares means for the milking frequency are given in Table 4 for both models, classified by parities and DIM classes. Frequencies were greatest for first parity. The effect of better locomotion because of fewer feet and leg disorders (König et al., 2005) and the effect of their smaller udder capacity are 2 plausible reasons for this difference. Milking frequency was greatest for the earliest DIM class, which agrees with results of Halm (2003) and Dzidic et al. (2004). Dzidic et al. (2004) divided the lactation stage into the same DIM as our study and reported frequencies of 2.93, 2.50, and 2.16 in DIM classes 1, 2, and 3, respectively. Dzidic et al. (2004) concluded an effect of higher milk yield in the early lactation stage on the milking frequency. Our model included milk production as a covariate. The effect of higher milking frequencies at the early stages of lactation thus seemed to be influenced by other factors, such as the human interference with cow movement. The association between the daily milk yield and daily milking frequencies is illustrated in Figure 2 for model 1 and shows a similar positive trend for all DIM classes. High milk yield increased cows' movement into the milking box. Even for the same values of daily milk yield in different DIM classes, milking frequencies were greatest in DIM class 1 and lowest in DIM class 3.

\section{Genetic Parameters}

The models with the AR(1) covariance structure for residual effects resulted in smaller estimates of heritability for milking frequency than with the CS model (Table 5). Heritabilities estimated with model 1 were moderate, ranging from 0.16 in DIM class 1 to 0.22 in DIM class 3 with the AR(1) model and from 0.17 to 0.23 with the CS model (Table 5). Sawalha et al. (2005a) also obtained smaller additive genetic and permanent environmental variances for yield traits with the AR(1) model than with the CS mode, resulting in smaller heritabilities. Heritabilities using average observations (model 2) were slightly greater than the values from

Table 4. Least square means for milking frequency by parities for different DIM classes using repeated measurements and the AR(1) covariance structure (model 1) and average observations (model 2) ${ }^{1}$

\begin{tabular}{|c|c|c|c|c|c|c|}
\hline \multirow[b]{2}{*}{ DIM } & \multicolumn{2}{|c|}{ Parity 1} & \multicolumn{2}{|c|}{ Parity 2} & \multicolumn{2}{|c|}{ Parity $>2$} \\
\hline & Model 1 & Model 2 & Model 1 & Model 2 & Model 1 & Model 2 \\
\hline 1 to 100 & $3.35^{\mathrm{a}}$ & $3.12^{\mathrm{a}}$ & $3.01^{\mathrm{b}}$ & $3.04^{\mathrm{b}}$ & $2.865^{\mathrm{c}}$ & $2.74^{\mathrm{c}}$ \\
\hline $\begin{array}{l}\text { (DIM class } 1) \\
101 \text { to } 200\end{array}$ & $\begin{array}{c} \pm 0.026) \\
3.26^{\mathrm{a}}\end{array}$ & $\begin{array}{c}( \pm 0.027) \\
3.03^{\mathrm{a}}\end{array}$ & $\begin{array}{c}( \pm 0.022) \\
2.95^{\mathrm{b}}\end{array}$ & $\begin{array}{c} \pm 0.027) \\
2.99^{\mathrm{b}}\end{array}$ & $\begin{array}{r}( \pm 0.021) \\
2.802^{\mathrm{c}}\end{array}$ & $\begin{array}{c}( \pm 0.026) \\
2.69^{\mathrm{c}}\end{array}$ \\
\hline (DIM class 2 ) & $( \pm 0.026)$ & $( \pm 0.027)$ & $( \pm 0.021)$ & $( \pm 0.030)$ & $( \pm 0.023)$ & $( \pm 0.028)$ \\
\hline 201 to 300 & $2.75^{\mathrm{a}}$ & $2.86^{\mathrm{a}}$ & $2.69^{b}$ & $2.80^{\mathrm{b}}$ & $2.551^{\mathrm{c}}$ & $2.48^{\mathrm{c}}$ \\
\hline (DIM class 3 ) & $( \pm 0.019)$ & $( \pm 0.024)$ & $( \pm 0.020)$ & $( \pm 0.026)$ & $( \pm 0.021)$ & $( \pm 0.024)$ \\
\hline
\end{tabular}

${ }^{\mathrm{a}-\mathrm{c}}$ Different superscript letters within DIM classes and models indicate significant differences $(P<0.01$, $t$-test).

${ }^{1} \mathrm{AR}(1)$ model assumes autoregressive covariance structure for milking frequency per day environmental effects. Standard errors of means are in parentheses. 
Table 5. Variance components, heritabilities, and standard error of heritabilities for milking frequency for different DIM classes using repeated measurements (model 1) and average observations (model 2)

\begin{tabular}{|c|c|c|c|c|c|c|c|c|c|}
\hline \multirow[b]{3}{*}{ Component } & \multicolumn{3}{|c|}{ DIM class 1} & \multicolumn{3}{|c|}{ DIM class 2} & \multicolumn{3}{|c|}{ DIM class 3} \\
\hline & \multicolumn{2}{|c|}{ Model $1^{1}$} & \multirow[b]{2}{*}{ Model 2} & \multicolumn{2}{|c|}{ Model $1^{1}$} & \multirow[b]{2}{*}{ Model 2} & \multicolumn{2}{|c|}{ Model $1^{1}$} & \multirow[b]{2}{*}{ Model 2} \\
\hline & $\operatorname{AR}(1)$ & CS & & $\mathrm{AR}(1)$ & CS & & $\operatorname{AR}(1)$ & $\mathrm{CS}$ & \\
\hline$\sigma_{a}^{2}$ & 0.083 & 0.088 & 0.058 & 0.087 & 0.089 & 0.086 & 0.084 & 0.087 & 0.070 \\
\hline$\sigma_{e}^{2}$ & 0.341 & 0.340 & 0.262 & 0.299 & 0.295 & 0.259 & 0.259 & 0.256 & 0.183 \\
\hline$\sigma_{p e}^{2}$ & 0.082 & 0.080 & - & 0.084 & 0.081 & - & 0.040 & 0.038 & - \\
\hline$\sigma_{p}^{2}$ & 0.506 & 0.508 & 0.320 & 0.470 & 0.465 & 0.343 & 0.383 & 0.381 & 0.246 \\
\hline $\mathrm{H}^{2}$ & 0.164 & 0.173 & 0.182 & 0.185 & 0.191 & 0.249 & 0.219 & 0.228 & 0.276 \\
\hline S.E.h ${ }_{h}^{2}$ & 0.041 & 0.041 & 0.039 & 0.052 & 0.051 & 0.048 & 0.049 & 0.049 & 0.048 \\
\hline
\end{tabular}

${ }^{1} \mathrm{CS}$ model is a simple repeatability model with compound symmetry covariance structure for milking frequency per day environmental effects; AR(1) model assumes autoregressive covariance structure for milking frequency per day environmental effects.

model 1 (Table 5). Higher heritabilities in the later stage of lactation were due to a substantial reduction of the residual component. Perhaps intervention by farmers in the early lactation stage was mandatory for acclimatization to the AMS, decreasing natural variability among cows, whereas in the later lactation stages cows were allowed to behave naturally to the milking process. A research design comparable with our study was developed by Baehr (1983). Baehr estimated a heritability of 0.55 for the entrance frequency of cows in a feeding station and of 0.28 for the length of time cows spent lying per day. Heritabilities for behavior or temperament of cows, based on subjective measures (Schutz and Pajor, 2001) and summarized in Table 1, were generally lower than the values found in our study.

Based on this combination of results, the amount of additive genetic variance in behavior is sufficient enough for breeding policies, but the integration of temperament in a combined breeding goal requires an exact definition of the trait. Temperament in dairy cattle can include milking behavior, easy handling, and the dominance or aggressiveness of cows. The traditional meaning of milking behavior concerns a cow's ability to be calm and easy to handle during the milking process. Sullivan and Burnside (1988) reported a positive genetic correlation of 0.74 between milking behavior and ease of handling. Our definition of behavior in terms of milking frequency in the milking box also incorporated the dominance or aggressiveness of cows. Cows having a lower rank or status within the herd are likely to be suppressed from the milking box by cows having a higher rank. Sullivan and Burnside (1988) estimated the genetic correlation between milking behavior and aggressiveness to be close to zero. Presupposing such a negligible genetic correlation between milking frequency and milking behavior, selection on milking fre- quency will have no detrimental effect on milkability. Nevertheless, for comprehensive development of breeding strategies, further investigation of relationships between different types of behavioral traits in AMS must be done.

Genetic correlations between milking frequency and other production traits are of substantial interest because selection in German dairy cattle is mainly focused on improved production (Rensing et al., 2002). Genetic correlations between milking frequency and daily milk yield were between 0.46 to 0.57 across DIM classes when AR(1) was applied (Table 6). These findings suggest that sires that have high EBV for production traits will tend to have daughters that come easily or voluntarily into the milking box. The positive genetic correlations for all DIM classes indicated that selection toward increased milk production would have desirable effects on the number of voluntary visits of cows in the milking box. However, the direct recording and genetic evaluation of temperament will ensure additional genetic gain when included in a comprehensive breeding goal with production and other functional traits. The derivation of economic weights for temperament is necessary, but this value should be positive for milking frequency because fetching cows to the AMS increases labor associated with milking by up to one-third (Trilk et al., 2005). The frequency of entrance of cows into an AMS is a measurement of behavior free of subjective impressions of investigators and could also contribute to the selection of cows for voluntary entry into conventional milking parlors.

Other studies estimating correlations between milk yield and behavior should be carefully compared with our results, because the definition of temperament differs between studies or experimental designs. Most estimates of genetic correlations between milk yield and milking temperament or between milk yield and social 
Table 6. Genetic correlations $\left(r_{\mathrm{g}}\right)$ between milking frequency (MF), milk yield (MY), and SCS for different DIM classes using repeated measurements and AR(1) covariance structure (model 1) and average observations ${ }^{1}$

\begin{tabular}{|c|c|c|c|c|c|c|}
\hline \multirow[b]{2}{*}{$\underline{r_{g}}$} & \multicolumn{2}{|c|}{ DIM class 1} & \multicolumn{2}{|c|}{ DIM class 2} & \multicolumn{2}{|c|}{ DIM class 3} \\
\hline & Model 1 & Model 2 & Model 1 & Model 2 & Model 1 & Model 2 \\
\hline MF: MY & $0.57( \pm 0.11)$ & $0.47( \pm 0.09)$ & $0.48( \pm 0.14)$ & $0.46( \pm 0.11)$ & $0.53( \pm 0.15)$ & $0.49( \pm 0.13)$ \\
\hline MF: SCS & $0.04( \pm 0.14)$ & $0.06( \pm 0.13)$ & $0.03( \pm 0.16)$ & $0.01( \pm 0.14)$ & $0.01( \pm 0.17)$ & $0.04( \pm 0.14)$ \\
\hline MY: SCS & $0.18( \pm 0.11)$ & $0.16( \pm 0.10)$ & $0.17( \pm 0.12)$ & $0.16( \pm 0.10)$ & $0.20( \pm 0.14)$ & $0.15( \pm 0.12)$ \\
\hline
\end{tabular}

${ }^{1} \mathrm{AR}(1)$ model assumes autoregressive covariance structure for milking frequency per day environmental effects. Standard errors or $r_{g}$ in parentheses.

dominance, respectively, have been near zero and therefore negligible (e.g., Dickson et al., 1970; Sewalem et al., 2002). However, Sullivan and Burnside (1988) found that cows that were genetically superior in production were more aggressive during the feeding process. Their reported correlations between EBV for milk yield and EBV for milking behavior and between EBV for milk yield and EBV for ease of handling were unfavorable. On the other hand, Visscher and Goddard (1994) analyzed workability traits of heifers scored by farmers on a 5-point linear scale. Good temperament and high likeability were genetically favorably associated with higher milk yield. The same result was found by Erf et al. (1992); overall satisfaction of cows and trouble-free workability were favorably correlated with fat-corrected milk. Considering these results, the question remains whether such owner surveys are the best method to evaluate the genetic background of behavior. Our attempt to characterize behavior in dairy cattle is relatively free from subjective impressions of farmers, but further analysis should focus on correlations between different types of temperament and to study the relationship between the milking frequency of cows in AMS and other aspects of behavior during the milking process.

In this study genetic correlations between milking frequency and SCS were near zero, regardless of the choice of model (Table 6). Estimates for genetic correlations were in the range of 0.01 to 0.06 . Devir et al. (1993) suggested using milking frequencies per day in the AMS as a control or management system (e.g., to monitor the status of udder health). However, our results do not support this theory; there was no genetic relationship between milking frequency and SCS, which indicates mastitis.

For completeness of results, genetic correlations between daily milk yield and SCS are also presented in Table 6 . The positive genetic correlation in a range of 0.15 to 0.20 confirmed results from previous studies (e.g., König et al., 2005) and indicates that selection or breeding on increased milk yield increases susceptibility to udder diseases.

\section{CONCLUSIONS}

The present study has clearly shown the genetic influence on one measure of dairy cattle behavior (frequency of voluntary entry into an AMS), and results were similar regardless of the model applied for analysis. Genetic parameters from analyses of repeated records using the AR(1) and CS covariance structures were in agreement with estimates based on averages of observations. Heritability estimates were high enough to allow for direct selection on the measure of behavior. The positive genetic correlation between daily milk yield and daily milking frequency indicated that continued selection for high production may increase the frequency with which cows go voluntarily into the AMS. Genetic correlations between milking frequency and SCS were near zero.

The inevitable desire to increase labor efficiency in dairy cattle farming as emphasized by Devir et al. (1993) and Trilk et al. (2005) as well as the increasing use of AMS in Germany demand that cows go easily to the milking station. Inclusion of aspects of behavior and temperament into breeding goals can make a contribution to the improvement of the welfare of animals and farmers. However, management and other environmental effects must also be considered. In this study, the fixed herd effect accounting for husbandry and feeding strategies was the most important factor in our study affecting the milking frequency of cows.

\section{ACKNOWLEDGMENT}

The authors thank the anonymous reviewers for their valuable suggestions to improve the manuscript.

\section{REFERENCES}

Agyemang, K., E. Clapp, and L. D. Van Vleck. 1982. Components of variance of dairymen's workability traits among Holstein cows. J. Dairy Sci. 65:1334-1338.

Akaike, H. 1973. Information theory and an extension of the maximum likelihood principle. In: B. N. Petrov and F. Csaki. Proc. 2nd Int. Symp. Inf. Theory. Akademiai Kiado, Budapest, Hungary.

Ali, A. K. A., and G. E. Shook. 1980. An optimum transformation for somatic cell concentration in milk. J. Dairy Sci. 63:487-490. 
Baehr, J. 1983. Verhalten von Milchkühen in Laufställen. PhD Dissertation, Christian-Albrecht University, Kiel, Germany.

Bohlsen, E. 2000. Erprobung und Bewertung Automatischer Melkverfahren (AMV) im Praxiseinsatz. PhD Dissertation, Göttingen, Germany.

Buchenauer, D. 1999. Genetics of Behavior in Cattle. In The Genetics of Cattle. CABI Publishing, Wallingford, UK.

Buenger, A., T. Pasman, E. Bohlsen, and F. Reinhardt. 2001.Transformation of AMS records to 24 hour equivalents. http://www.vit.de/ Additor/Binary173/24_h_yield_from_AMS.pdf Accessed Nov. 20, 2005.

Burnside, E. B., S. B. Kowalchuk, D. B. Lambroughton, and A. E. Freeman. 1971. Canadian dairy cow disposals: 1 . Differences between breeds, parity and seasons. Can. J. Anim. Sci. 51:75-83.

Devir, S., J. A. Renkema, R. B. M. Huirne, and A. H. Ipema. 1993. A new dairy control and management system in the automatic milking farm: Basic concepts and components. J. Dairy Sci. 76:3607-3616.

Dickson, D. P., G. R. Barr, L. P. Johonson, and D. A. Wieckert. 1970. Social dominance and temperament of Holstein cows. J. Dairy Sci. 75:904-907.

Dzidic, A., D. Weis, and R. M. Bruckmaier. 2004. Oxytocin release, milk ejection and milking characteristics in a single stall automatic milking system. Livest. Prod. Sci. 86:61-68.

Erf, E. F., L. B. Hansen, and D. A. Lawstuen. 1992. Inheritance and relationships of workability traits and yield for Holsteins. J. Dairy Sci. 75:1999-2007.

Faure, J. M. 1994. Behavioral genetics: An overview. Proc. 5th World Congr. Genet. Appl. Livest. Prod., Guelph, Canada. 20:129.

Foster, W. W., A. E. Freeman, P. J. Berger, and A. L. Kuck. 1988. Linear type traits with genetic parameter estimation. J. Dairy Sci. 71:223-231.

Gauly, M., H. Mathiak, K. Hoffmann, M. Kraus, and G. Erhardt. 2004. Estimating genetic variability in temperamental traits in German Angus and Simmental cattle. J. Anim. Behav. Sci. 74:109-119.

Gilmour, A. R., B. J. Gogel, B. R. Cullis, and R. Thompson. 1998. ASReml User Guide. Release 1.0. NSW Agriculture, Orange, Australia.

Gregory, K. E., G. L. Bennet, L. D. Van Vleck, S. E. Echternkamp, and L. V. Cundiff. 1997. Genetic and environmental parameters for ovulation rate, twinning rate, and weight traits in a cattle population selected for twinning. J. Anim. Sci. 75:1213-1222.

Gustafsson, M. 2004. Working time studies in farms with conventional and automatic milking. Page 488 in Automatic milkingA better understanding. Wageningen Academic Publishers, Wageningen, the Netherlands.

Halm, H. 2003. Zum Einfluss eines automatischen Melkverfahrens auf Milchmengenleistung und Milchinhaltssoffe hochleistender DH-Kühe unter Berücksichtigung von Laktationsstadium und Eutergesundheit. PhD Dissertation, University of Veterinary Medicine, Hannover, Germany.

Hohenboken, W. D. 1986. Inheritance of behavioral characteristics in livestock. A review. Anim. Breed. Abstr. 54:623-639.

Huisman, A. E., R. F. Veerkamp, and J. A. M. van Arendonk. 2001. Genetic parameters of various random regression models to describe the weight data of pigs. J. Anim. Sci. 80:575-582.
König, S., R. A. Sharifi, H. Wentrot, D. Landmann, M. Eise, and H. Simianer. 2005. Genetic parameters of claw and foot disorders estimated with logistic models. J. Dairy Sci. 88:3316-3325.

Lawstuen, D. A., L. B. Hansen, G. R. Steuernagel, and L. P. Johnson. 1988. Management traits scored by dairy producers. J. Dairy Sci. 71:788-795.

Le Neindre, P., G. Trillat, J. Sapa, F. Menissier, J. N. Bonnet, and J. M. Chupin. 1995. Individual differences in docility in Limousin cattle. J. Anim. Sci. 73:2249-2253.

Littell, R. C., P. R. Henry, and C. B. Ammerman. 1997. Statistical analysis of repeated measures data using SAS procedures. J. Anim. Sci. 76:1216-1231.

Littell, R., G. Milliken, W. Stroup, and R. Wolfinger. 1999. SAS system for mixed models. SAS Institute Inc., Cary, NC.

Quaas, R. L. 1984. Linear Prediction. Pages 1-76 in BLUP School Handbook. Animal Genetics and Breeding Unit, Univ. New England, NSW, Australia.

Rensing, S., E. Pasman, F. Reinhardt, and E. Feddersen. 2002. New total merit index for Holsteins in Germany with more emphasis on herd life. Interbull Bull. 29:147-150.

Rydhmer, L. 2005. Genetics and behavior. Livest. Prod. Sci. 93:1-2.

Sawalha, R. M., J. F. Keown, S. D. Kachman, and L. D. Van Vleck. 2005a. Evaluation of autoregressive covariance structures for test-day records of Holstein cows: Estimates of parameters. J. Dairy Sci. 88:2632-2642.

Sawalha, R. M., J. F. Keown, S. D. Kachman, and L. D. Van Vleck. 2005 b. Genetic evaluation of dairy cattle with test-day models with autoregressive covariance structures and with a 305-d model. J. Dairy Sci. 88:3346-3353.

Schutz, M. M., and E. A. Pajor. 2001. Genetic control of dairy cattle behavior. J. Dairy Sci. 84(E. Suppl.):E31-E38.

Sewalem, A., G. Kistemaker, and B. Van Doormal. 2002. Bayesian inferences for milking temperament in Canadian Holsteins. Commun. no. 01-50 in Proc. 7th World Congr. Genet. Appl. Livest. Prod.

Sharifi, A. R. 2004. Reproduktives Adaptationsvermögen von BroilerMuttertieren bei hohen Umwelttemperaturen unter Nutzung spezieller Majorgene. PhD Dissertation, Humboldt University, Berlin, Germany.

Sullivan, B. P., and E. B. Burnside. 1988. Can we change the temperament in the dairy cow? Online. Available: http://cgil.uoguelph.ca/ pub/articles/temp.html Accessed Nov. 12, 2005.

Thompson, J. R., A. E. Freeman, D. J. Wilson, C. A. Chapin, P. J. Berger, and A. Kuck. 1981. Evaluation of linear type program in Holsteins. J. Dairy Sci. 64:1610-1617.

Trilk, J., R. Zube, and D. May. 2005. Management, Kostenaufwand und Wirtschaftlichkeit Automatischer Melksysteme in Auswertung mehrjähriger praktischer Nutzung. Züchtungskunde 77:256-270.

Visscher, P. M., and M. E. Goddard. 1994. Genetic parameters for milk yield, survival, workability, and type traits for Australian dairy cattle. J. Dairy Sci. 78:205-220.

Wade, K. M., and R. L. Quaas. 1993. Solution to a system of equations involving a first-order autoregressive process. J. Dairy Sci. 76:3026-3032. 